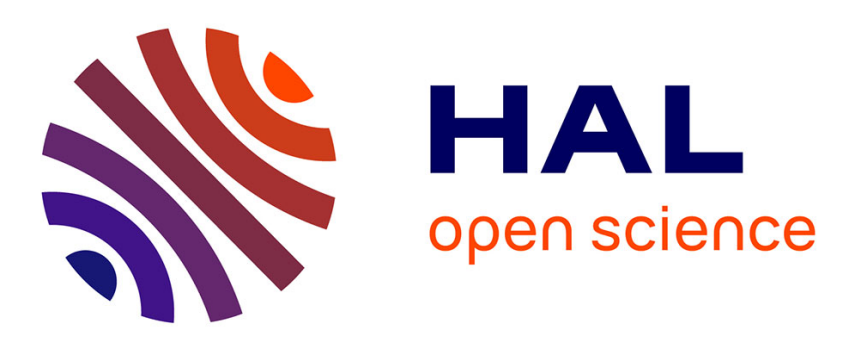

\title{
Partial Cavities: Global Behavior and Mean Pressure Distribution
}

Le Quang, Jean-Pierre Franc, Jean-Marie Michel

\section{To cite this version:}

Le Quang, Jean-Pierre Franc, Jean-Marie Michel. Partial Cavities: Global Behavior and Mean Pressure Distribution. Journal of Fluids Engineering, 1993, 115 (2), pp.243-248. 10.1115/1.2910131. hal-01133776

\section{HAL Id: hal-01133776 \\ https://hal.science/hal-01133776}

Submitted on 2 Sep 2020

HAL is a multi-disciplinary open access archive for the deposit and dissemination of scientific research documents, whether they are published or not. The documents may come from teaching and research institutions in France or abroad, or from public or private research centers.
L'archive ouverte pluridisciplinaire HAL, est destinée au dépôt et à la diffusion de documents scientifiques de niveau recherche, publiés ou non, émanant des établissements d'enseignement et de recherche français ou étrangers, des laboratoires publics ou privés. 


\section{Partial Cavities: Global Behavior and Mean Pressure Distribution}

The results of an experimental work concerning the behavior of flows with partial cavities are presented. The tests were carried out using a plano-convex foil placed in the free surface channel of the I.M.G. Hydrodynamic Tunnel. The experimental conditions concerning ambient pressure, water velocity, and body size were such that various and realistic kinds of flows could be realized. The main flow regimes are described and correlated to the values of foil incidence and cavitation parameter. Attention is paid to the shedding of large vapor pockets into the cavity wake and its possible periodic character. Aside from classical consideration to the cavity length and shedding frequency in the periodic regime, results concerning the wall pressure distribution in the rear part of the cavity are given. They lead to distinguish thin, stable, and closed cavities from the thick ones in which the reentrant jet plays a dominant role for the shedding of vortical structures and the flow unsteadiness.
Q.Le ${ }^{1}$

J. P. Franc

J. M. Michel

Laboratoire des Ecoulements Géophysiques et Industriels, Institut de Mécanique de Grenoble, 38041 Grenoble cédex, France

\section{Introduction}

From a number of years the cavitating flow regime has become more and more accepted in hydraulic manufacturing, for example for first stage inducers of pumps used either in common industrial situation or in more advanced technology. Such an evolution in the industrial viewpoint involves that cavitation is taken in account from the first stage of the machine design. In particular, it requires that cavitating flows can be modeled in order to make possible the performance prediction for machines at off-design points together with the estimate of cavitation erosion risk. That requirement is still far from being fulfilled at the present time. For example, it is known (Furuya, 1980; Yamaguchi and Kato, 1983; Ito, 1986; Lemonnier and Rowe, 1988) that modeling of partial, steady cavities is not simple: due to the inverse character of the flow representation in the vicinity of the cavity and its wake, several numerical solutions can be built inside the framework of potential theory, each one depending on the particular boundary conditions which are adopted in that region. An additional difficulty arises from the open or closed character of the cavity wake which results in variations of the drag coefficient. Thus, in the simple case of two-dimensional flow around a partially cavitating hydrofoil, it happens that the prediction of global parameters such as cavity length and forces coefficients, given the wall geometry and the cavitation number, is not always possible. As regards the risk of erosion, only little is known on the flow agressivity and its link with the mean flow regime.

We present here the results of an experimental study (Le Q.,1989) intended to increase the available information on the basic two-dimensional partially cavitating flows which can be encountered on most blades of hydraulic rotating machinery. The present paper is concerned with the global behavior and the mean aspects of the flow, especially in the cavity closure

\footnotetext{
'Now at the National Polytechnic Institute, Hanoi, Vietnam.
}

region, while the results of pressure peak measurements are the subject of a second paper in the same issue of the Journal. It is believed that such results can be used as a guide for the choice of a flow model and the estimate of damage potential.

Partial cavities are described with some details in the textbook by Knapp et al. (1970) which emphasizes the cyclic regime with shedding of large vapor structures at the rear of the cavity. The same viewpoint is adopted by Lush and Peters (1982) for cavities attached at the throat of a converging-diverging duct. For those authors, the shedding is due to the development of an instability at the cavity interface, whereas for Furness and Hutton (1975) the leading mechanism is reentrant jet. A detailed study of large vapor structures shedding, using laser anemometry and conditional sampling, was presented by $\mathrm{Ku}-$ bota et al. (1987). The same technique was used by Avellan and Dupont (1988) in order to describe the velocity field in the vicinity of rather short and stable partial cavities at high Reynolds number. Nguyen The (1986) established that measurements of wall mean pressure in the case of cavitating flows were feasible with ordinary devices; he gave a detailed description of the cyclic regime and found an almost constant value for the Strouhal number based on the cavity length.

In the present work, we classify the different cavitating regimes which appear at the upper side of a plane-convex hydrofoil according to the values of both cavitation number and angle of attack. Special attention is paid to the following topics: cavity length, shedding frequency, and mean pressure profile at the rear of the cavity. The Reynolds number is between 1 and 2.4 million so that the configuration is expected to be significant for most industrial situations.

\section{Experimental Setup}

The Hydrodynamic Tunnel is described by Briançon-Marjollet and Michel (1990). The foil was placed in the second test section (depth $40 \mathrm{~cm}$, width $12 \mathrm{~cm}$ ) at a submersion depth of $20 \mathrm{~cm}$ under the free surface. Its upper side is plane and its 


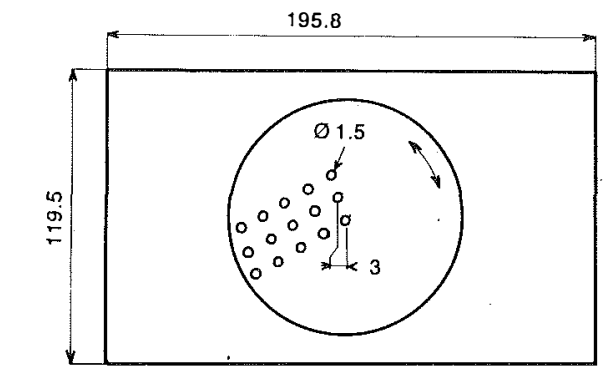

$\stackrel{v}{\longrightarrow}$

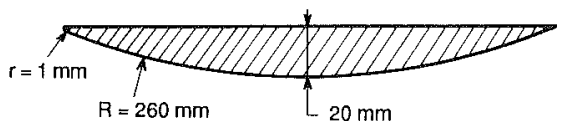

Fig. 1

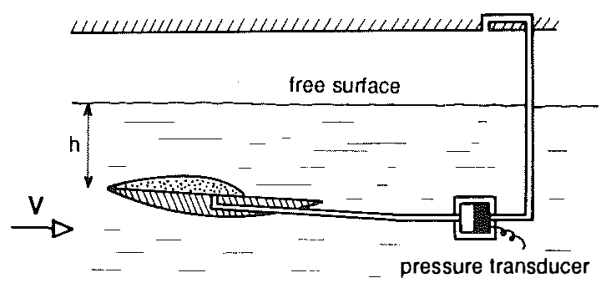

Fig. 2

lower side circular (radius $26 \mathrm{~cm}$ ) with a maximum thickness of $2 \mathrm{~cm}$. The leading edge is rounded with a radius of $1 \mathrm{~mm}$ so that the chord is about $196 \mathrm{~mm}$. A circular plate on which pressure holes or pressure transducers are implanted can be rotated at the foil upper side (Fig. 1). It allows us to make measurements in the region of the cavity closure at abscissae between 54 and $138 \mathrm{~mm}$ as counted from the leading edge.

Most of the tests were made with water velocities of 5 and $10 \mathrm{~m} / \mathrm{s}$ to which correspond Reynolds numbers of about $10^{6}$ and $2.10^{6}$, respectively. The value of the cavitation number $\sigma_{v}$ could be then established in the range 0.05-1.3. Partial cavities on the foil upper side were obtained by varying the angle of attack between -6 and +8 deg. As seen on Fig. 3, developed cavities were also present near the trailing edge at the foil lower side. They could be accompanied by transient explosive bubbles: the rough foil shape results in pressure coefficients of about -1 which are sufficient to activate air nuclei with critical pressure lower than $-20,000 \mathrm{~Pa}$. In the present paper however the main interest is focused to upper side cavities. Measuring the local mean pressure along the cavity closure region is not an obvious task. After some attempts it appeared that the classical method using pressure holes (1.5 $\mathrm{mm}$ in diameter) can be adopted if holes are followed by short pipes and a chamber where static pressure is measured by a pressure transducer (see Fig. 2), even though some bubbles are present into the tubes. The errors resulting from differences in the water column height can be reduced to a negligible value if all the measuring line is placed at the same altitude. That was systematically checked by injecting a small amount of air in the measuring line: the

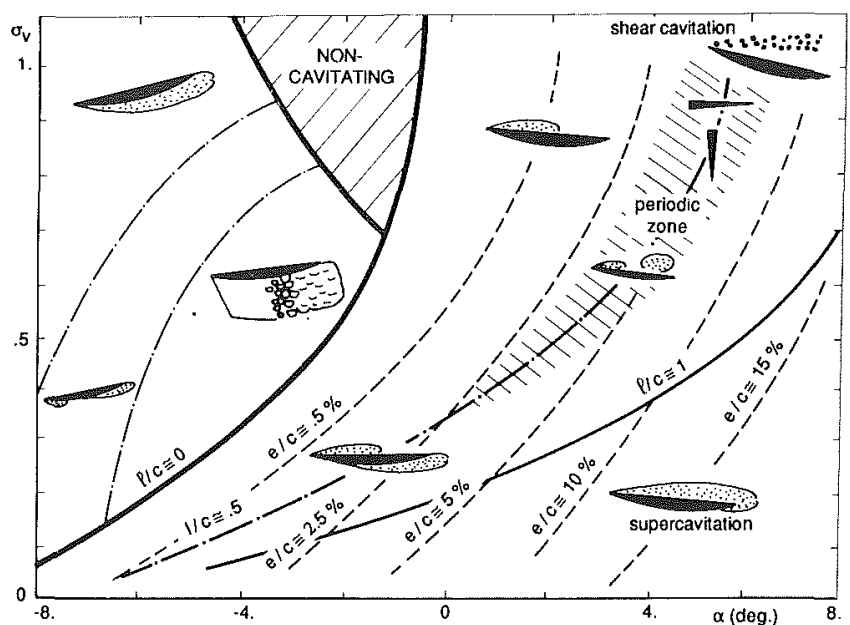

Fig. 3 Main cavitation patterns at $\mathrm{Re}=2 \times 10^{\circ}$

transducer output signal did not show any appreciable variation when water or air were present in the pipe.

Then the measurements can be repeated without any appreciable variation. Fifteen holes were drilled on the rotating plate at abscissae differing by $3 \mathrm{~mm}$ in order to obtain the pressure profiles.

\section{Global Behavior of Partial Cavities}

3.1 Cavitation Patterns. Figure 3 shows the main cavitation patterns with reference to the values of the incidence $\alpha$ and the cavitation number $\sigma_{v}$, the Reynolds number Re being close to $2.10^{6}$ (for other values of $\mathrm{Re}$, the results are not significantly modified). The domain of interest is between the curves $l=0$ and $l=c(l$ is the cavity length at the foil upper side as measured under natural light, $c$ is the chord). Those curves are relative to incipient cavitation and supercavitation, respectively. The curves of equal relative cavity thickness $e / c$ are also shown. The shedding of large vapor structures corresponds to $e / l$ greater than 0.05 approximately. On the contrary, periodical shedding is limited to the shaded area. Thus it is visible that shedding is not necessarily cyclic. On Fig. 3, the direction of increasing frequency for variable incidence or variable pressure is indicated by two narrow triangles: as expected, the frequency decreases when $l$ is increased.

When varying both parameters $\alpha$ and $\sigma_{v}$ we can keep $l$ constant and observe the subsequent variations of the thickness $e$ : such variations can be seen on Fig. 4 for $l=72 \mathrm{~mm}$ or $l /$ $c=0.37$.

3.2 Cavity Length. The relation between the cavity length and the cavitation number, either for partial or super cavities, is presented in Fig. 5.

For cavities with shedding of vapor structures, the maximum length is concerned. In the region of large cavity lengths, above 70 to $100 \mathrm{~mm}$, the slope of curves is large, particularly for the small $\sigma_{v}$ : then large variations of the flow geometry are com-

\section{Nomenclature}

$c=$ foil chord

$e=$ cavity thickness

$f=$ shedding frequency

$h=$ foil submersion depth

$l=$ cavity length

$$
\begin{aligned}
p_{0}= & \text { pressure at the channel free } \\
& \text { surface } \\
p_{v}= & \text { vapor pressure } \\
U= & \text { channel water velocity } \\
\alpha= & \text { foil incidence } \\
\mu= & \text { water viscosity }
\end{aligned}
$$

$$
\begin{aligned}
\rho= & \text { water density } \\
\operatorname{Re}= & \rho c U / \mu: \text { Reynolds number } \\
\sigma_{v}= & 2\left[p_{0}+\rho g h-p_{v}\right] / \rho U^{2}: \text { cavita- } \\
& \text { tion parameter } \\
C_{p}= & 2\left[p-\left(p_{0}+\rho g h\right)\right] / \rho U^{2}: \text { pres- } \\
& \text { sure coefficient }
\end{aligned}
$$




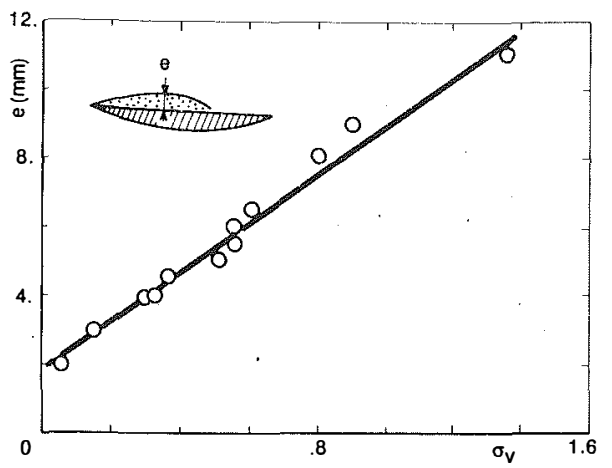

Fig. 4 Cavity thickness versus cavitation number $(I \equiv 72 \mathrm{~mm})$

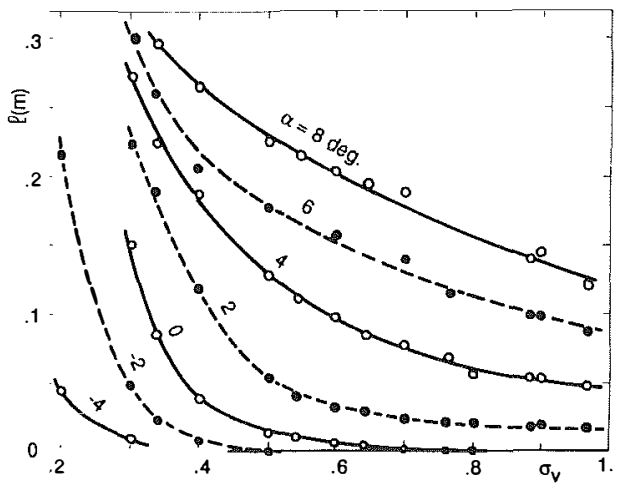

Fig. 5 Cavity length versus cavitation number

patible with small changes in the pressure gradient. That fact is favorable to appearance of flow unsteadiness.

All the experimental points collapse well enough around a unique curve (see Fig. 6) if $1 / c$ is represented versus the nondimensional parameter: $\sigma_{v} /\left[\alpha-\alpha_{i}\left(\sigma_{v}\right)\right]$, where $\alpha_{i}\left(\sigma_{v}\right)$ corresponds to the curve $l=0$ in FIg. 3. Recall the parameter $\sigma_{v} /$ $\alpha$ is introduced by the linearized theory which considers that for a slender body the cavitation number is proportional to the angle of attack at a constant cavity length. Here the incidence is corrected by its value at cavitation inception.

Experimental results concerning the relation between the cavity length and the relative cavity under pressure are currently used to support model results. It must be noted here that the parameter $H \sigma_{v}$ does not always represent the correct value of the cavity under pressure. Thus results of Figs. 5 and 6 have to be used with consideration to the parameter $\Delta \sigma$ which will be introduced in Fig. 13.

3.3 Periodic Shedding. By means of high speed films the kinematics of shedding over a period can be observed (Fig. 7). In the most regular cases, the attached cavity grows during about two thirds of the period while the vapor pocket released at the initial instant near the leading edge is conveyed downstream. It explodes firstly as described by Kubota et al. (1987), and then collapses at time $t=2 \mathrm{~T} / 3$. At this instant the reentrant jet starts to flow upwards. An important point is that the new vapor structure is shed into the wake at the instant when the reentrant jet reaches the vicinity of the leading edge.

Indeed, as the cavity inside cannot be seen, the existence of reentrant jet is not obvious. In a first step it was inferred from perturbations of the cavity surface travelling against the main flow at a speed almost equal to $U$ with $U=10 \mathrm{~m} / \mathrm{s}$, i.e., at a relative velocity not far from $20 \mathrm{~m} / \mathrm{s}$ : such a value cannot be easily understood unless motion of subjacent material particles is called for. In a second step, water colored with fluorescein was injected into the cavity through a pressure hole at

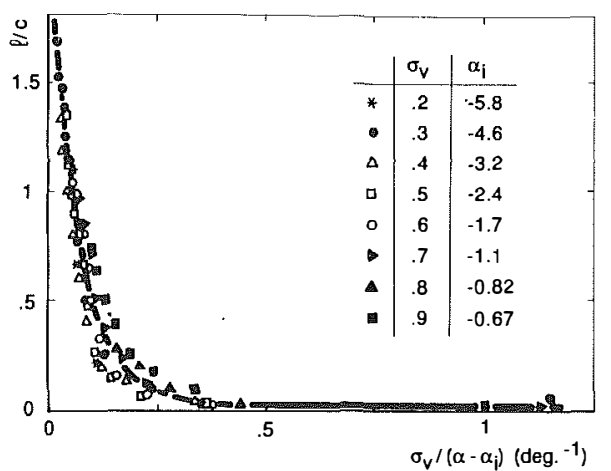

Fig. 6 Cavity length versus nondimensional parameter $\sigma_{v} /\left(\alpha-\alpha_{i}\right)$

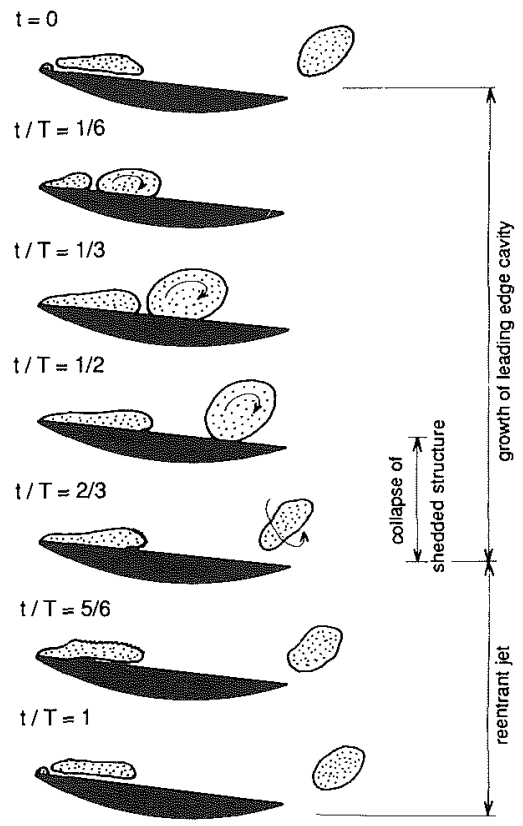

Fig. 7 Periodic shedding mechanism

the abscissa $x=84 \mathrm{~mm}$, the maximum cavity length being 90 $\mathrm{mm}$ and the incidence $4,5 \mathrm{deg}$.

Then it became clear that cyclic reentrant jet was present since colored water could be seen near the leading edge at some instants of the period and only around the vapor pocket shed into the wake at other instants.

The Strouhal number $S=f l / U$, where $f$ is the shedding frequency measured under stoboscopic light, is found to be almost constant, its value turning around 0.28 , as shown on Fig. 8. That fact tends to confirm the role of the reentrant jet in the shedding of vapor structures. Let $\beta U$ the reentrant jet velocity and $l / \beta U$ the time required to cover the cavity length. This time is approximately equal to $T / 3$ (see Fig. 7) so that we can estimate the $\mathrm{S}$-value by $\mathrm{S}=\beta / 3$ which gives 0.3 for $\beta$ $=0.9$. In general the $\beta$-value decreases with the cavity thickness and for the thinner cavities the reentrant jet does no longer reach the leading edge: both effects contribute to keep nearly constant the Strouhal number.

Potential flows of inviscid fluids with free surfaces exhibit reentrant jet as a typical feature (e.g., Efros, 1946, Gilbarg and Serrin, 1950). More, as discussed by Benjamin and Ellis (1966), the reentrant jet, when reaching an opposite free surface, results in the formation of a doubly connected liquid domain which makes possible the appearance of new circulation. Thus, reentrant jet contributes to the shedding of circulation into the cavity wake together with other mechanisms 


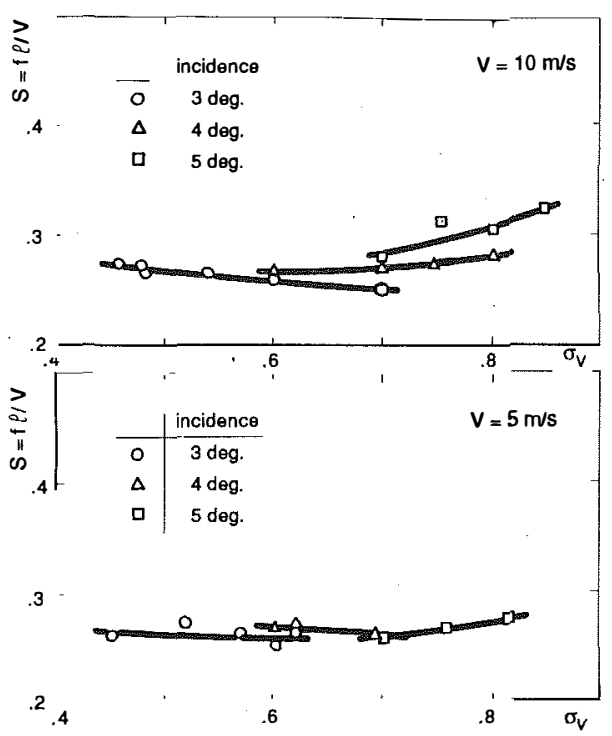

Fig. 8 Strouhal number versus cavitation number

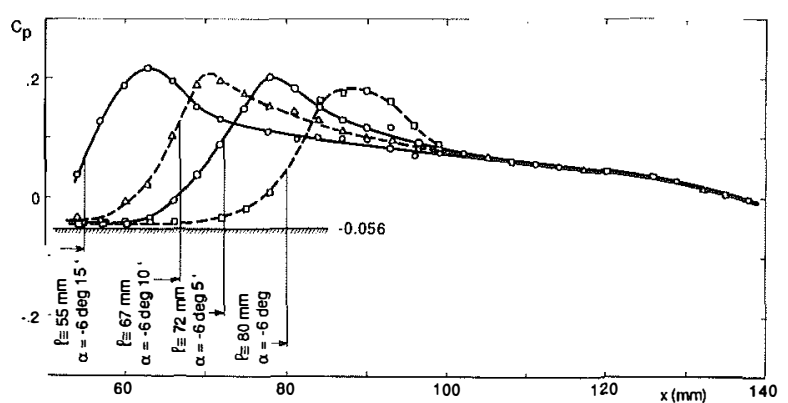

Fig. 9 Pressure coefficient distribution for $\sigma_{v}=0.056$ and $V=10 \mathrm{~m} / \mathrm{s}$

related to the actual viscous behavior of the liquid (Franc and Michel, 1985; Avellan and Dupont, 1988). That contribution can be easily estimated: as shown in Fig. 7, when a vapor pocket is shed downstream, it rolls as a vortical structure and ultimately is transformed in a rough horseshoe vortex before collapsing. The circulation around each vapor pocket is estimated as $\gamma\left(\sqrt{1+\sigma_{v}}+\beta\right) l U$ where $\gamma l$ is the part of the cavity length covered by the reentrant jet. Thus the production rate of circulation is approximately $\gamma\left(\sqrt{1+\sigma_{v}}+\beta\right) S U^{2}$. The coefficient of $U^{2}$ is about 0.6 for the thick partial cavities having a well formed reentrant jet; it becomes smaller when the cavity is thinner.

The case of large vapor pockets shed without any periodicity was observed but not studied in a detailed way. There is no phase regulator in that case but reentrant jet probably is still responsible of pocket shedding. If this conjecture is correct, the characteristic time of shedding can still be estimated by an expression such as $\gamma l / \beta U$.

3.4 Mean Pressure in the Cavity Closure Region. Figures 9,10 , and 11 show the pressure distributions which are obtained for three values of the cavitation number, respectively, .056, .55 , and .81 . In each case the different cavity lengths correspond to varying angles of attack. An overpressure is seen near the cavity end for the smallest value of $\sigma_{v}$. It disappears progressively when $\sigma_{v}$ increases. Roughly speaking, the overpressure corresponds to the thin, stable cavities while cavities with large vapor pockets shedding don't present the pressure maximum. Both kinds of cavities can be called closed and open, respectively. The disappearance of the overpressure can be attributed either to the motion of the cavity closure or to pure unsteady effects.

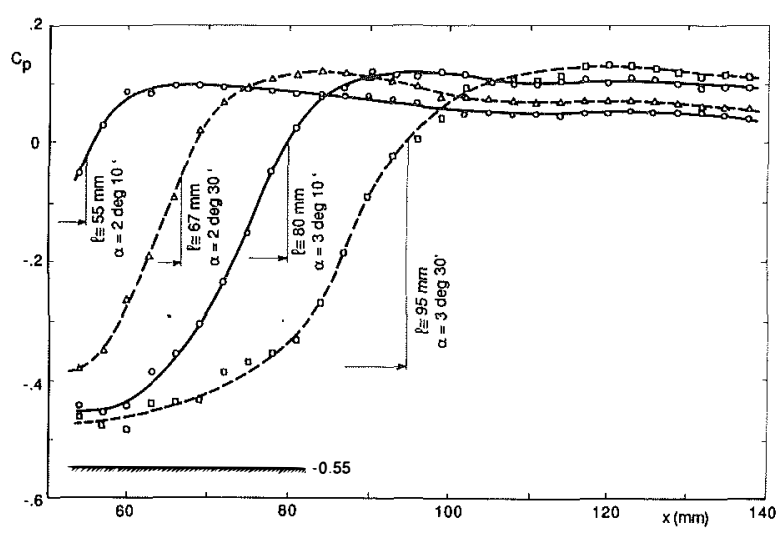

Fig. 10 Pressure coefficient distribution for $\sigma_{v}=0.55$ and $V=10 \mathrm{~m} / \mathrm{s}$

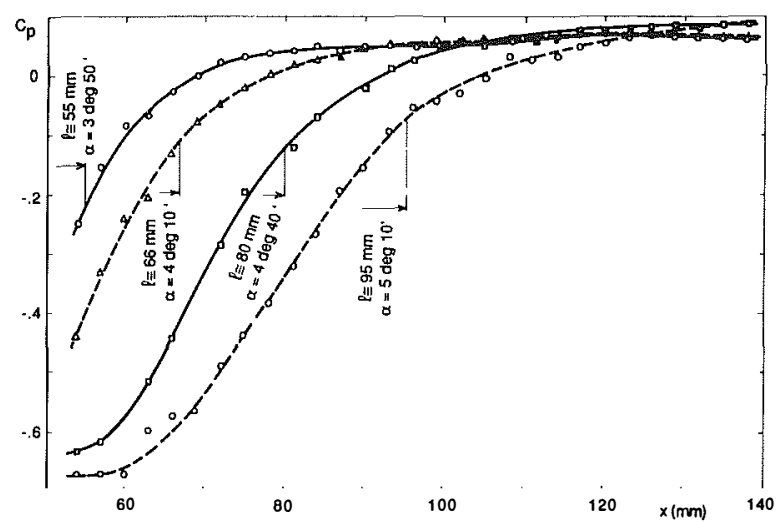

Fig. 11 Pressure coefficient distribution for $\sigma_{v}=0.81$ and $V=10 \mathrm{~m} / \mathrm{s}$

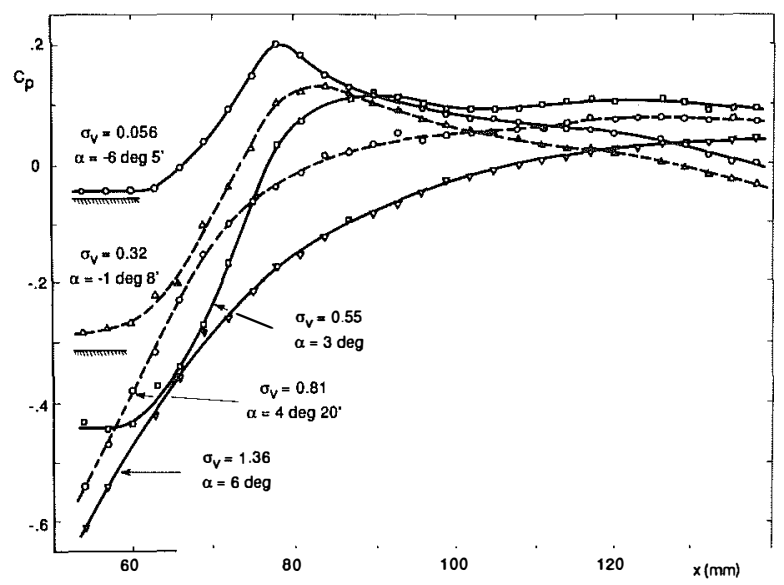

Fig. 12 Influence of partial cavitation pattern on pressure coefficient distribution at constant cavity length $(I \cong 72 \mathrm{~mm})$

The evolution of the pressure distribution when $\sigma_{v}$ changes, the cavity length keeping the same value $72 \mathrm{~mm}$, is shown on Fig. 12. For $\sigma_{v}=1.36$, it is more cavitation in the separated shear layer than a true cavity, but the pressure distribution seems to be in continuity with other cases: the cavity oscillation, with emission of vaporous vortical structures, finally leads to the structure of open recirculation zone.

In Figs. 9 to 12, we can observe firstly that the pressure coefficient is not always constant in the region corresponding to the cavity. Secondly, when it is constant, its value $C p c$ is not necessarily equal to the expected value $-\sigma_{v}$, the difference becoming larger for the open cavities. That is due to the presence of water in front of the pressure hole at some instants of 


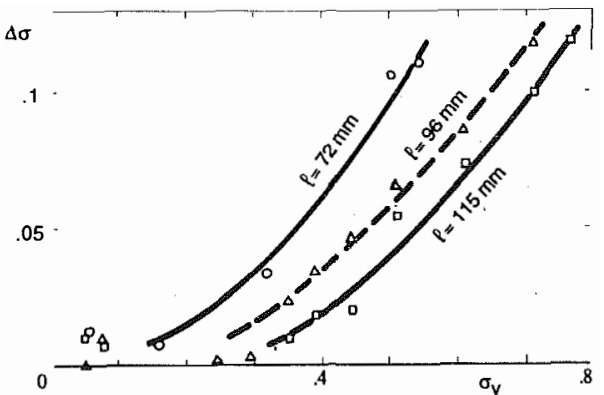

Fig. 13 Variation of difference $\Delta \sigma$ versus $\sigma_{v}$

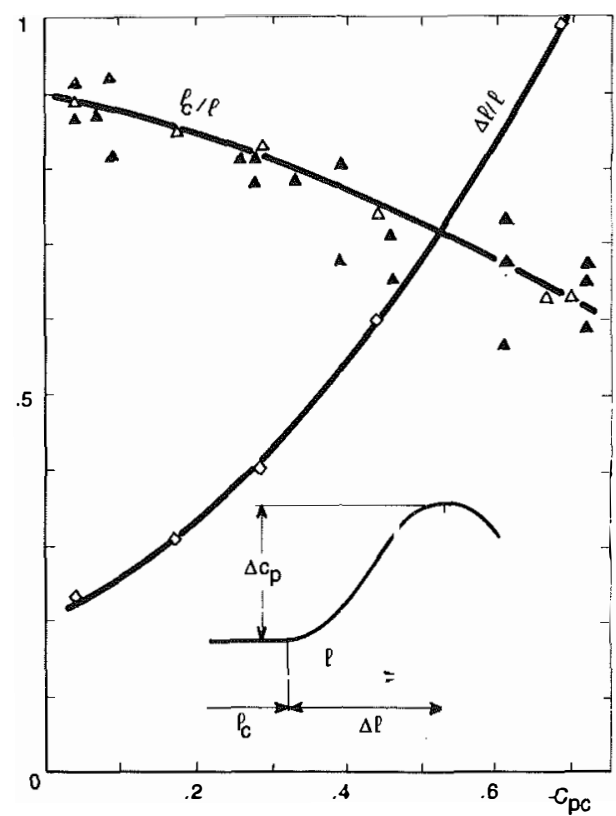

Fig. 14 Variation of ratios $|c| \mid$ and $\Delta|/|$ versus $-C_{p c}$

the cycle. Then, in order to describe more precisely the cavity and its wake, it becomes useful to consider the following quantities:

- $l c$, the length corresponding to a constant value of the pressure coefficient

- $\Delta l$, the difference between the abscissa of the maximum pressure coefficient and $l c$

- $\Delta \sigma$, the difference $C p c+\sigma_{v}$

- $\Delta C p$, the difference between the maximum value of $C p$ in the near wake of the cavity and $C p c$

Figure 13 shows the variations of $\Delta \sigma$ versus the cavitation number $\sigma_{v}$ for several values of the cavity length. The difference $\Delta \sigma$ can reach the value 0.2 .

In Fig. 14 are presented the ratios $l c / l$ and $\Delta l / l$ versus $|C p c|$. The first ratio decreases and the second one increases as $|C p c|$ becomes larger, i.e., the cavity becomes more and more open. At the same time, the difference $\Delta C p$ also increases as shown in Fig. 15, although the pressure maximum is removed far from the cavity closure.

\section{Concluding Remarks}

The closed or open character of the cavity end, which is particularly visible on pressure distributions, seems to be connected to the behavior of the reentrant jet and thus to the cavity thickness. In case of thick cavities, the jet can go against the main flow over a significant part of the cavity length and

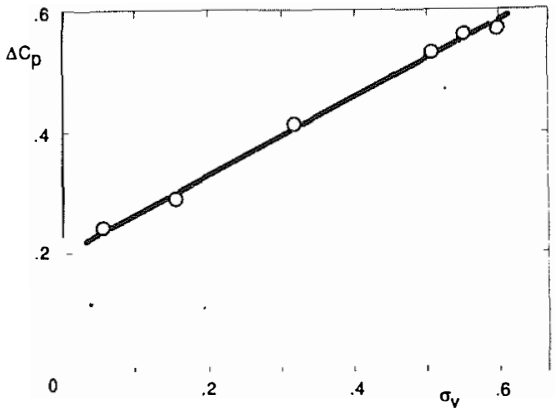

Fig. 15 Variation of difference $\Delta C_{p}$ versus $\sigma_{v}(I=72 \mathrm{~mm}-V=10$ $\mathrm{m} / \mathrm{s}$ )

contribute to the detachment of a large vapor pocket. Contrarily, this counterflow is not possible in case of thin cavities firstly because the jet momentum is very small and secondly because the space available for its motion is narrow: friction between adjacent layers prevents a large development of the jet. This one is confined to a small region near the cavity closure and flow unsteadiness does not spread far from there.

The reentrant jet is associated to the production of vorticity: in case of periodic cavities, the shedding rate of circulation by that mechanism can be estimated.

From the viewpoint of modeling, the closed or open cavities correspond to different boundary conditions (Lemonnier and Rowe, 1988; Favre, 1988; Yamaguchi and Kato, 1989). It is known that closed models give rise to a maximum of the pressure coefficient near the cavity end. For example, such a model was used by the first author (Le, 1989) in order to adjust some model free parameters with reference to the experimental values of $\Delta l$ and $\Delta C p$. More generally, the present results tend to restrict the field of application of closed models to steady flow around stable, thin cavities whereas a model taking the flow unsteadiness in account will be more appropriate for open cavities.

\section{Uncertainties}

The errors on the parameters $V, \alpha, \sigma_{v}, p_{0}, \mathrm{Re}$, which define the experimental conditions, can be considered small. For example, $\Delta \alpha=.1 \mathrm{deg}, \Delta V=.03 \mathrm{~m} / \mathrm{s}, \Delta V / V=.3$ percent for $V=10 \mathrm{~m} / \mathrm{s}$. Taking the error on the pressure in account, we find $\Delta \sigma_{v} / \sigma_{v}$ of the order one percent.

The precision on frequency is good also (error less than 1 percent) when the periodic regime is well established. For other parameters (cavity lengths $l$ and $l c$, cavity thickness $e$, pressure coefficient $C_{p}$ ), the errors depend on the cavitating regimes: smaller for closed, stable cavities, larger for open cavities. The range of uncertainties is then between 2 and 10 percent.

\section{References}

Avellan, F., and Dupont, P., 1988, “Etude du sillage d'une poche de cavitation partielle se développant sur un profil hydraulique bi-dimensionnel," La Houille Blanche, No. 7/8, pp. 507-515.

Briançon-Marjollet, L., and Michel, J.M., 1990, "The Hydrodynamic Tunnel of I.M.G.: Former and Recent Equipments," ASME JournaI. OF Fluids ENGINEERING, Vol. 113, No. 3, pp. 338-342.

Benjamin, T. B., and Ellis, A. T., 1966, “The Collapse of Cavitation Bubbles and the Pressures Produced Against Solid Boundaries," Phil. Trans. Royal Soc. (London), Series A 260, pp. 221-240.

Efros, D., 1946, "Hydrodynamical Theory of Two-Dimensional Flow with Cavitation,"' C. R. Ac. Sc. URSS, Vol. LI, No. 4, pp. 267-270.

Favre, N., 1988, "Résolution du problème inverse par petites perturbations d'un écoulement potentiel incompressible," Thése, EPFL1010, Lausanne, June 1988.

Franc, J. P., and Michel, J. M., 1985, “Attached Cavitation and the Boundary Layer: Experimental Investigation and Numerical Treatment," Journal of Fluid Mechanics, Vol. 154, pp. 63-90.

Furness, R. A., and Hutton, S. P., 1975, "Experimental and Theoretical 
Studies of Two-Dimensional Fixed-Type Cavities," ASME Journal of Fluids ENGINEERING, Vol. 97, No. 4, pp. 515-522.

Furuya, O., 1980, "Non-Linear Theory for Partially Cavitating Cascade

Flows," IAHR 10th Symp., Tokyo, Proceedings, pp. 221-241.

Gilbarg, D., and Serrin, J., 1950, "Free Boundaries and Jets in the Theory

of Cavitation," Journal of Mathematics and Physics, Vol. 29, pp. 1-12.

Golden, D. W., 1975, "A Numerical Method for Two-Dimensional Cavitating

Flow," MIT Dept. of Ocean Eng., Rep. No. 81512-1.

Ito, J., 1986, "Calculation of Partially Cavitating Thick Hydrofoil and Examination of a Flow Model at Cavity Termination," International Symposium on Cavitation, Sendai, Proceedings, pp. 209-214.

Knapp, R. T., Daily, J. N., and Hammitt, F. G., 1970, Cavitation, McGrawHill, New York.

Kubota, S., Kato, H., Yamaguchi, H., and Maeda, M., 1987, "Unsteady Structure Measurement of Cloud Cavitation on a Foil Section Using Conditional
Sampling Technique," International Symposium on Cavitation Research Facilities and Techniques, Boston, Dec. 1987, Proc., pp. 161-168.

Le, Q., 1989, "Etude Physique du Comportement des Poches de Cavitation Partielle," Thesis, INPG, Grenoble, Sept.

Lemonnier, H., and Rowe, A., 1988, "Another Approach in Modelling Cavitating Flows," Journal of Fluid Mechanics, Vol. 195, Oct., pp. 557-580.

Lush, P. A., and Peters, P. I., 1982, "Visualisation of the Cavitating Flow in a Venturi-Type Duct using High Speed Cine Photography," International Association for Hydraulic Research Symposium, Amsterdam, Sept., Proceedings, Vol. 1, No. 5.

Nguyen, The M., 1986, "Fermetures de Poches de Cavitation Partielle: Cinematique-Pressions à la Paroi," These, Grenoble, Oct.

Yamaguchi, H., and Kato, H., 1983, "On Application of Non Linear Cavity Flow Theory to Thick Foil Section," IME, 2nd Conference on Cavitation, Edinburgh, Sept., Proceedings, pp. 167-174. 